\title{
Tazarotene-Induced Gene 1 (TIG1) Interacts with Serine Protease Inhibitor Kazal-Type 2 (SPINK2) to Inhibit Cellular Invasion of Testicular Carcinoma Cells
}

\author{
Rong-Yaun Shyu, ${ }^{1}$ Chun-Hua Wang $\mathbb{D},{ }^{2,3}$ Chang-Chieh Wu, ${ }^{4}$ Lu-Kai Wang $\mathbb{D}^{5}$ \\ Mao-Liang Chen, ${ }^{6}$ Chan-Yen Kuo, ${ }^{6}$ Ming-Cheng Lee, ${ }^{6}$ Yi-Ying Lin, ${ }^{6}$ and Fu-Ming Tsai ${ }^{6}{ }^{6}$ \\ ${ }^{1}$ Department of Internal Medicine, Taipei Tzuchi Hospital, The Buddhist Tzuchi Medical Foundation, New Taipei City 231, Taiwan \\ ${ }^{2}$ Department of Dermatology, Taipei Tzuchi Hospital, The Buddhist Tzuchi Medical Foundation, New Taipei City 231, Taiwan \\ ${ }^{3}$ School of Medicine, Tzu Chi University, Hualien 970, Taiwan \\ ${ }^{4}$ Department of Surgery, Tri-Service General Hospital Keelung Branch, National Defense Medical Center, Keelung 202, Taiwan \\ ${ }^{5}$ Radiation Biology Core Laboratory, Institute for Radiological Research, Chang Gung University, Chang Gung Memorial Hospital, \\ Linkou, Taoyuan 333, Taiwan \\ ${ }^{6}$ Department of Research, Taipei Tzuchi Hospital, The Buddhist Tzuchi Medical Foundation, New Taipei City 231, Taiwan
}

Correspondence should be addressed to Fu-Ming Tsai; afu2215@gmail.com

Received 3 May 2019; Revised 23 July 2019; Accepted 5 August 2019; Published 25 November 2019

Academic Editor: Torsten Goldmann

Copyright (c) 2019 Rong-Yaun Shyu et al. This is an open access article distributed under the Creative Commons Attribution License, which permits unrestricted use, distribution, and reproduction in any medium, provided the original work is properly cited.

\begin{abstract}
Tazarotene-induced gene 1 (TIG1) encodes a protein that is a retinoid-regulated tumor suppressor. TIG1 is expressed in most normal tissues, and downregulation of TIG1 expression in multiple cancers is caused by promoter hypermethylation. Kazal-type serine protease inhibitor-2 (SPINK2) is a serine protease inhibitor, and the SPINK protein family has been shown to inhibit the expression of urokinase-type plasminogen activator (uPA). In addition, increased levels of uPA and the uPA receptor were observed in testicular cancer tissues. This study demonstrated that TIG1 interacts with SPINK2 in NT2/D1 testicular carcinoma cells. TIG1 and SPINK2 were highly expressed in normal testis tissues, while low expression levels of TIG1 and SPINK2 were found in testicular cancer tissues. TIG1 inhibited cell invasion, migration, and epithelial-mesenchymal transition (EMT) of NT2/D1 cells. SPINK2 enhanced TIG1-regulated uPA activity and EMT suppression, while silencing SPINK2 alleviated TIG1-mediated EMT regulation, cell migration, and invasion. Therefore, the results suggest that the interaction between TIG1 and SPINK2 plays an important role in the inhibition of testicular cancer cell EMT, and suppression is mediated through downregulation of the uPA/uPAR signaling pathway.
\end{abstract}

\section{Introduction}

Tazarotene-induced gene 1 (TIG1), also known as retinoic acid receptor responder 1 (RARRES1), is a retinoic acid regulated tumor suppressor gene [1]. Downregulation of TIG1 in multiple cancers is mediated by common CpG hypermethylation in the TIG1 promoter region [2-7]. TIG1 belongs to the latexin family of putative cytoplasmic carboxypeptidase inhibitors, and it has been shown to regulate the $\alpha$-tubulin tyrosination cycle via the ATP/GTP binding protein-like 2 (AGBL2) protein [8].

In addition to regulation of $\alpha$-tubulin, which is related to mitochondrial function, ectopic TIG1 exhibits cell growth suppression and induction of autophagy in cervical, colon, and nasopharyngeal cancer cells [9-13]. Microarray analysis of mifepristone-inducible TIG1 expression in colon cells revealed $\mathrm{G}$ protein-coupled receptor kinase 5 (GRK5)-mediated TIG1-induced cell growth suppression through the Wnt and cAMP signaling pathways $[9,10]$. The heat shock protein DNAJC8 and the transmembrane protein 192 have been shown to participate in TIG1-mediated glycolysis metabolism and autophagy regulation $[11,12]$. Knockdown of TIG1 leads to enhanced invasion capacity of HK1-EBV nasopharyngeal cells [13]; however, the underlying mechanism of cell invasion mediated by TIG1 is still unclear. 
The serine protease inhibitor Kazal-type protein family contains a Kazal domain located at the C-terminus, which is an evolutionary conserved protein domain of the serine protease inhibitor. SPINK1 has been considered a tumor-associated trypsin inhibitor, and overexpression of SPINK1 is a predictor of unfavorable outcomes in ovarian [14], prostate [15], liver [16], breast [17], and colon [18] cancers. In contrast, SPINK6 has been found to inhibit tumorigenesis in human hepatocellular carcinoma via the regulation of ERK1/2 activation [19]. SPINK-induced activities, which contribute to tumor growth, could be related to its target proteins, such as Kallikrein-related peptidase (KLK). KLK-mediated tumor growth is believed to modulate plasmin formation through the urokinase plasminogen-type activator (uPA) system [20]. Loss of SPINK7 has been shown to increase uPA activity in esophageal epithelial cells [21], indicating that SPINK7 may represent a key checkpoint in regulating mucosal barrier function in esophageal cells. Similarly, a recent study has shown that downregulation of SPINK13 promotes metastasis through the uPA system in ovarian cancer cells [22].

Numerous studies have demonstrated the activity of carboxypeptidase inhibitors in TIG1-mediated regulation of inflammation and mitochondrial function $[8,23]$. We also identified TIG1 as a regulator of glucose metabolism via DNAJC8 and PKM2 proteins [11]. However, the mechanism by which TIG1 is involved in migration, invasion, or metastasis remains unknown. We used a yeast two-hybrid screen to demonstrate that TIG1 interacts with SPINK2. Because the SPINK protein family has been shown to inhibit uPA activity, which may contribute to epithelial-to-mesenchymal transition (EMT) and tumor metastasis, we hypothesized that SPINK2 might participate in TIG1-mediated inhibition of cancer cell invasion. Therefore, the current study investigated whether TIG1 affects the activity of uPA, which is negatively regulated by SPINK2, potentially preventing EMT and suppressing cell migration and invasion.

\section{Materials and Methods}

\subsection{Quantitative Reverse Transcription PCR (RT-}

QPCR). Human total RNA was purchased from Takara Bio USA, Inc. (San Jose, CA). Testis RNA samples were derived from four normal testis cells, three testicular embryonal carcinomas, and three testicular seminomas from Origene Technologies (Rockville, MD). Then, $1.5 \mu \mathrm{g}$ of RNA was first reverse transcribed into cDNA, and quantitative PCR was performed. Briefly, reverse transcription reactions were conducted in $20 \mu \mathrm{L}$ reaction mixtures containing $50 \mathrm{mM}$ Tris- $\mathrm{HCl}$ ( $\mathrm{pH}$ 8.3), $75 \mathrm{mM} \mathrm{KCl,} 3$ mM MgCl $2,10 \mathrm{mM}$ DTT, $2 \mu \mathrm{M}$ oligo $(\mathrm{dT})_{12-18}, 0.5 \mathrm{mM}$ dNTP, and 10 units of M-MLV reverse transcriptase (Invitrogen, Carlsbad, CA). The cDNA mixture was incubated at $37^{\circ} \mathrm{C}$ for $1 \mathrm{~h}$, and the enzyme was subsequently inactivated by heating at $72^{\circ} \mathrm{C}$ for $15 \mathrm{~min}$. Quantitative PCR was then performed in triplicate in a $20 \mu \mathrm{L}$ reaction mixture containing $50 \mathrm{ng}$ cDNA, $10 \mu \mathrm{L}$ Fast SYBR Green Master Mix (Applied Biosystems, Foster City, CA), and $100 \mathrm{nM}$ of TIG1- or SPINK2-specific primers. PCR cycling conditions were as follows: a denaturing incubation at $95^{\circ} \mathrm{C}$ for 1 min followed by 40 cycles of denaturing at $95^{\circ} \mathrm{C}$ for $15 \mathrm{~s}$ and annealing and extension at $60^{\circ} \mathrm{C}$ for $1 \mathrm{~min}$. These amplifications were performed in a thermal cycler $(7900 \mathrm{HT}$ Fast Real-Time PCR System, Applied Biosystems). PCR primers used for amplification included the following: TIG1 (5'-CGTGGTCTTCAGCACAGAGCG-3' and $5^{\prime}$-CCCAA ACGTCCCTCACCTTCC-3'), SPINK2 (5'-TACCTTCGC AGCCTCTCTGA-3' and 5'-AGCAGGGTCCATTTCGA ATGAT- $3^{\prime}$ ), and actin ( $5^{\prime}$-TCCCTGGAGAAGAGCTACG-3' and $5^{\prime}$-GTAGTTTCGTGGATGCCACA- $3^{\prime}$ ). Expression levels of TIG1 and SPINK2 were normalized to the mean of actin expression level.

2.2. Expression Vectors and SiRNAs. The pTIG1myc-his expression vector was previously described [9]. To generate the pSPINK2-flag expression vector, SPINK2 cDNA was first amplified from human NT2/ D1 testicular cancer cells using SPINK2-specific primers (5'-TGGCTAGCATGGCGCTGTCGGTGCTGCGC- ${ }^{\prime}$ ' and 5'-GACTCGAGGCAGGGTCCATTTCGAATGATTTTA-3'). The amplified SPINK2 cDNA was then digested with Nhe I and Xho I followed by subcloning into the Nhe I-Xho I sites of the PCR3.1-Flag vector. All SPINK2 siRNAs targeted against nucleotides 391-409 (5'-GAATGTACTCTGTGCATGA-3'), nucleotides 496-514 (5'-CACCTTCACTGGCAGACTA- $\left.3^{\prime}\right)$, and nucleotides 508-526(5'-CAGACTAGATAAATTGCAT-3 $\left.{ }^{\prime}\right)$ were based on the GenBank accession NM_021114.3 and were synthesized by Sigma (Saint Louis, MO).

2.3. Cell Culture and Transfection. NT2/D1 testicular carcinoma cells were purchased from Bioresource Collection and Research Center (Hsinchu, Taiwan). NT2/ D1 cells were cultured in Dulbecco's Modified Essential Medium (DMEM) containing $2 \mathrm{mM}$ L-glutamine, 100 units/ $\mathrm{mL}$ penicillin and streptomycin, and $10 \%$ fetal bovine serum (FBS) at $37^{\circ} \mathrm{C}$ in $5 \% \mathrm{CO}_{2}$. For transfection, cells were first cultured in 24-well or 6-well plates at a density of $2 \times 10^{4}$ or $1 \times 10^{5}$ cells per well overnight. Plasmids and X-tremeGENE HP DNA Transfection Reagent (Sigma) were diluted in DMEM without serum at room temperature for 10-15 min. The X-tremeGENE HP DNA Transfection Reagent and plasmid complexes were then added to cells without removing the culture medium. Cell lysates were prepared $24 \mathrm{~h}$ after transfections were performed. Alternatively, cells were cultured in serum-free DMEM for an additional $12 \mathrm{~h}$ after cells were transfected for $24 \mathrm{~h}$. Cells were subsequently harvested for cell migration and invasion assays.

2.4. Cell Viability Assay. NT2/D1 cells were cultured in 24-well plates overnight. Cells were then transfected with $250 \mathrm{ng}$ pTIG1-myc-his expression vector along with $250 \mathrm{ng}$ empty control vector or pSPINK2-flag expression vector for $24 \mathrm{~h}$. The cells were cultured in DMEM without serum for $12 \mathrm{~h}$ followed by $24 \mathrm{~h}$ incubation in medium containing $1 \%$ FBS. Cells were incubated in the presence of the WST-1 reagent (Roche Diagnostics, Mannheim, Germany) for an additional $4 \mathrm{~h}$. Culture medium was collected, and the absorbance (450-650 nm) of each 
sample was determined with a multifunctional microplate reader (Infinite F200, Tecan, Durham, NC, USA).

2.5. Cell Migration and Invasion Assays. NT2/D1 cells were seeded into 6-well plates overnight. Cells were then transfected with $1 \mu \mathrm{g}$ of expression vectors along with $30 \mu \mathrm{M}$ siRNAs for $24 \mathrm{~h}$. After incubation for $24 \mathrm{~h}$ followed by serum-free starvation for $12 \mathrm{~h}$, cells were collected and reseeded in DMEM without serum at a density of $2 \times 10^{4}$ cells per well in the upper transwell insert with an $8 \mu \mathrm{m}$ pore size (Falcon, Becton Dickinson). In the cell invasion assay, $5 \mu \mathrm{g} / \mu \mathrm{L}$ matrix-gel (Becton Dickinson, Franklin Lakes, New Jersey) was coated onto a transwell insert, followed by cell seeding in the polycarbonate membrane insert. DMEM with $20 \%$ FBS was used as a chemoattractant in the lower well in both the cell invasion and migration assays. After $24 \mathrm{~h}$ of incubation, cells were fixed with methanol for $10 \mathrm{~min}$ at room temperature and were immediately placed at $-20^{\circ} \mathrm{C}$ for overnight incubation. Cells were then stained with a $50 \mu \mathrm{g} /$ $\mathrm{mL}$ solution of propidium iodide (Sigma) for $30 \mathrm{~min}$. After cells were washed twice with PBS, the number of cells on each transwell membrane was examined with a Nikon ECLIPSE 80i microscope (Nikon Instruments Inc., Melville, NY).

2.6. Immunoprecipitation and Western Blotting. Cells were plated in $10 \mathrm{~cm}$ dishes at a density of $2 \times 10^{6}$ cells per dish overnight. After $24 \mathrm{~h}$ of transfection with $3 \mu \mathrm{g}$ TIG1-mychis and $3 \mu \mathrm{g}$ SPINK2-flag expression vectors, cell lysates were prepared in modified RIPA buffer (20 mM Tris- $\mathrm{HCl}$ [pH 7.5], $100 \mathrm{mM} \mathrm{NaCl}, 1 \% \mathrm{NP}-40,30 \mathrm{mM}$ sodium pyrophosphate) containing protease and phosphatase inhibitors. Cell lysate $(500 \mu \mathrm{g})$ proteins were incubated with $1 \mu \mathrm{g}$ of an anti-c-MYC (Sigma) or an anti-FLAG (Sigma) antibody at $4^{\circ} \mathrm{C}$ for $2 \mathrm{~h}$, followed by the addition of $20 \mu \mathrm{L}$ of protein $\mathrm{G}$ plus/protein A-agarose (Calbiochem, Cambridge, MA). Samples were then incubated at $4^{\circ} \mathrm{C}$ for an additional $2 \mathrm{~h}$. Alternatively, cell lysate $(5 \mathrm{mg})$ proteins were first incubated with $2 \mu \mathrm{g}$ of an anti-TIG1 antibody (Santa Cruz Biotechnology, Santa Cruz, CA) or an anti-SPINK2 antibody (GeneTex Inc., Irvine, $\mathrm{CA}$ ) and were then incubated with protein $\mathrm{G}$ plus/ protein A-agarose at $4^{\circ} \mathrm{C}$ for $2 \mathrm{~h}$. Samples were then washed with PBS three times, and immunoprecipitated complexes were then analyzed by western blotting. For western blotting, immunoprecipitated complexes or 15-50 $\mu \mathrm{g}$ of cell lysate protein was resuspended in Laemmli buffer and then run on $12-15 \%$ SDS-PAGE gels. Proteins were separated by SDSPAGE followed by electrotransfer to polyvinylidene fluoride membranes. Membranes were incubated in blocking buffer (5\% nonfat dry milk, $0.1 \%$ Tween-20 in $1 \mathrm{x}$ PBS) at room temperature for $1 \mathrm{~h}$ followed by incubation in blocking buffer with anti-MYC, anti-FLAG, anti-TIG1, anti-SPINK2, anti-E-cadherin (Santa Cruz Biotechnology), anti-vimentin (Santa Cruz Biotechnology), or anti-actin (Sigma) antibody at $4^{\circ} \mathrm{C}$ for $12 \mathrm{~h}$. After washing with $1 \mathrm{x}$ PBS containing $0.1 \%$ Tween-20 three times, membranes were incubated with horseradish peroxidase-conjugated goat anti-mouse or antirabbit antibodies at room temperature for $1 \mathrm{~h}$. After washing, target protein bands were visualized by chemiluminescence
(ECL detection kit, Amersham Biosciences, Bucks, UK), and images were subsequently analyzed with a ChemiDoc ${ }^{\text {TM }}$ XRS+ System (Bio-Rad Laboratories, Hercules, CA).

2.7. Immunofluorescence Staining. Cells were seeded onto polylysine-coated coverslips in 6 -well plates at $37^{\circ} \mathrm{C}$ overnight. After $24 \mathrm{~h}$ of transfection with $500 \mathrm{ng}$ of TIG1-myc-his expression vector and $500 \mathrm{ng}$ of SPINK2-flag expression vector, cells were washed with 1x PBS and were fixed with 4\% paraformaldehyde in $1 \mathrm{x}$ PBS. Cells were then permeabilized with $0.1 \%$ Triton X-100 for $5 \mathrm{~min}$ on ice followed by blocking with 1x PBS containing 2\% BSA at room temperature for 30 min. Cells were incubated in 1x PBS containing 2\% BSA with either the anti-c-MYC or anti-Flag antibody at $4^{\circ} \mathrm{C}$ for $12 \mathrm{~h}$ followed by incubation in 1x PBS containing 2\% BSA with the secondary antibodies Alexa Fluor 633 anti-mouse IgG and Alexa Fluor 488 anti-rabbit IgG (Invitrogen) at room temperature for $2 \mathrm{~h}$. After washing three times with $1 \mathrm{x}$ PBS, cells were stained with DAPI and analyzed for TIG1-MYC and SPINK2-FLAG expression with a confocal microscope (Leica TCS SP5 scanner, Bensheim, Germany).

2.8. Measurement of $u P A$ Activity. Cells were seeded in triplicate into 6-well plates in complete medium at $37^{\circ} \mathrm{C}$ overnight. After $24 \mathrm{~h}$ of transfection with the expression vectors or siRNAs, cells were incubated in serum-free DMEM for $24 \mathrm{~h}$. Cell lysates were harvested, and uPA activity was determined using a SensoLyte AFC uPA activity assay kit (AnaSpec, San Francisco, CA).

2.9. Statistical Analysis. Results are expressed as mean \pm SDs of at least three replicates. Statistical significance was determined by a one-way ANOVA, and a $p$-value $<0.05$ indicated a statistically significant difference.

\section{Results}

3.1. Downregulated TIG1 and SPINK2 Expression in Testicular Carcinoma Cells. To explore the possible role of TIG1 and SPINK2 in regulating cell function, the distribution of TIG1 and SPINK2 in thirteen different normal tissues was first analyzed. TIG1 was highly expressed in testis, bone, uterus, and lung tissues, while SPINK2 mRNA was only detected in testicular tissues (Figure 1(a)). Since TIG1 and SPINK2 are highly expressed in testis tissue, we next detected their mRNA expression in normal testicular cells, testicular embryonal carcinomas, and testicular seminomas (Figure 1(b)). Decreased gene expression in TIG1 and SPINK2 was observed in cancer tissues, indicating that TIG1 and SPINK2 might participate in cancer development in testicular tissue.

\subsection{TIG1 and SPINK2 Inhibit Cell Migration and Invasion in} NT2/D1 Testicular Carcinoma Cells. Because of the decreased expression of TIG1 and SPINK2 in testicular carcinoma tissue, the effects of TIG1 and SPINK2 on cell viability in NT2/D1 cells were further determined. NT2/D1 cells were transfected 


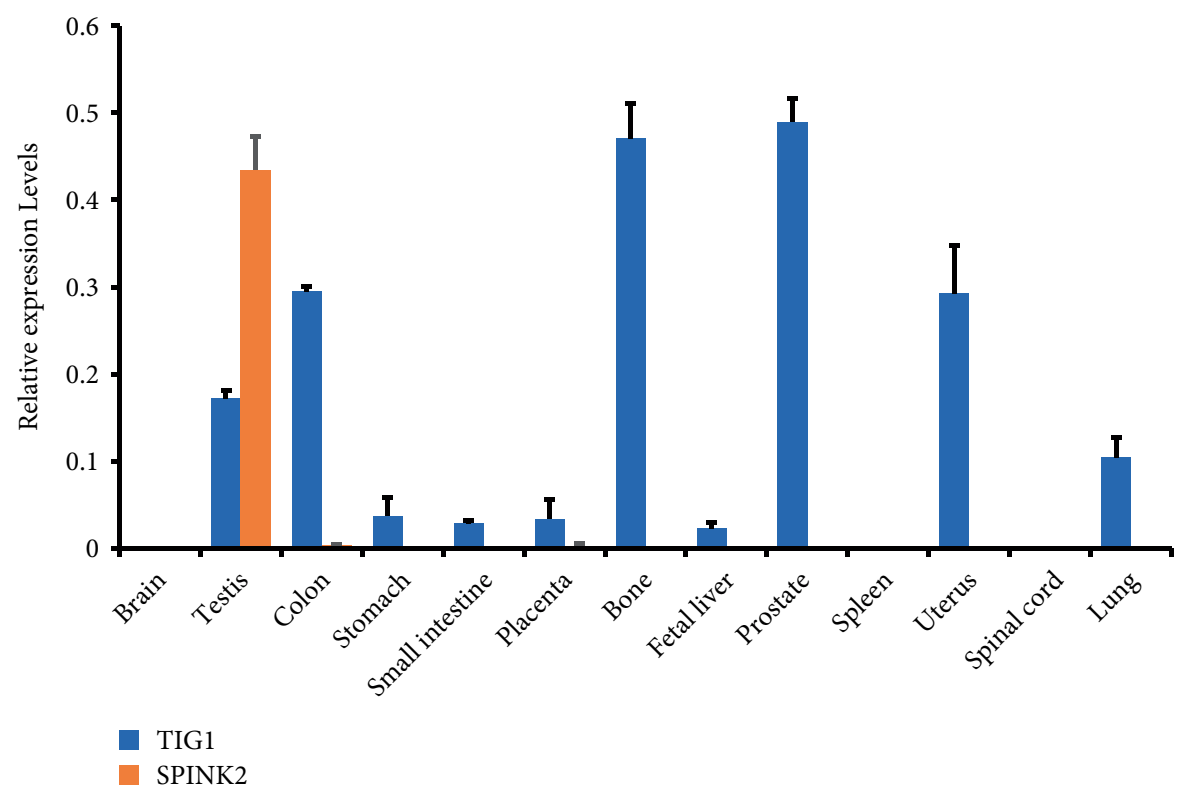

(a)

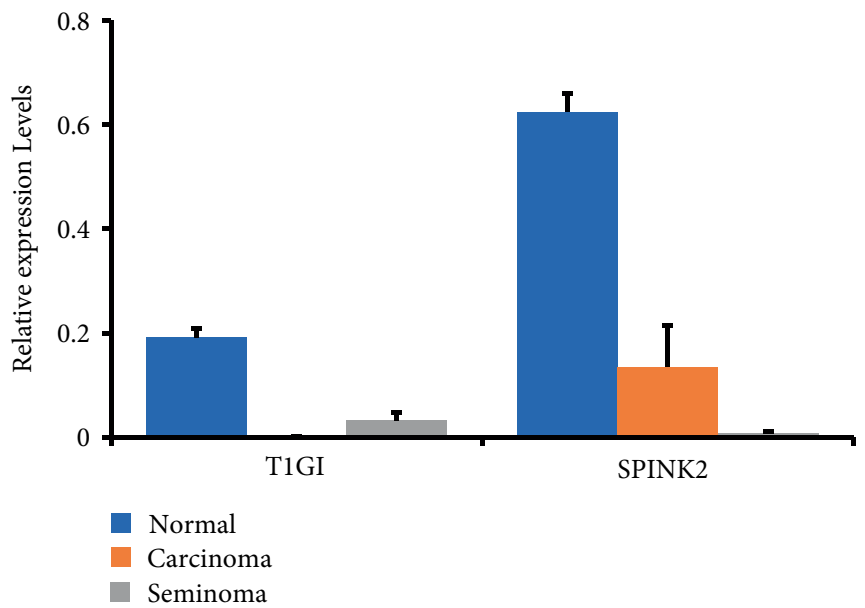

(b)

FIGURE 1: TIG1 and SPINK2 are highly expressed in testis tissues. Amplified cDNA samples prepared from total RNA of 13 different normal human tissues (a) or from total RNA of 4 normal, 3 carcinoma, or 3 seminoma tissues (b). Expression levels of TIG1 and SPINK2 were analyzed by quantitative real-time PCR. After normalizing expression to $\beta$-actin, relative expression levels are shown.

with TIG1-myc-his or SPINK2-flag expression vectors for 24-48 $\mathrm{h}$, and cell viability was examined using the WST-1 reagent. We detected no significant difference in cell viability in NT2/D1 cells expressing either TIG1-MYC or SPINK2FLAG (Figure 2(a)). In addition, no cell death was observed, as determined by LDH release assays, in NT2/D1 cells transfected with TIG1 or SPINK2 expression vectors for 24-48 h (data not shown). In contrast, TIG1 or SPINK2 expression in NT2/ D1 cells significantly inhibited cell migration by $56.4 \%$ and $42.9 \%$, respectively, compared to cell migration of NT2/D1 cells transfected with empty control vector. Furthermore, the number of migrated cells decreased by $57.4 \%$ in TIGland SPINK2 coexpressing cells compared to cells transfected with TIG1-myc expression vector for $24 \mathrm{~h}$ (Figure 2(b) and Supplementary Table S1). Additionally, cell invasion decreased by $82.9 \%$ and $69.2 \%$ in NT2/D1 cells transfected with either the
TIG1 or SPINK2 expression vector, respectively. Coexpressing TIG1 and SPINK2 in NT2/D1 cells further suppressed cell invasion by $78 \%$ compared to cell invasion of TIG1-expressing cells (Figure 2(c) and Supplementary Table S1).

3.3. TIG1 Associates with SPINK2. Interaction of TIG1 and SPINK2 was examined in a yeast two-hybrid screen. To confirm the interaction between TIG1 and SPINK2 within cells, coimmunoprecipitation was performed. TIG1-MYC was pulled down using anti-MYC antibody from the lysates of NT2/ D1 cells cotransfected with TIG1-myc-his and SPINK2-flag expression vectors for $24 \mathrm{~h}$. Coimmunoprecipitation results revealed that SPINK2-FLAG was present in the TIG1-MYC immunoprecipitated complexes (Figure 3(a)). Similarly, TIG1MYC was incorporated into the SPINK2-FLAG complexes, as determined by a pull-down assay using an anti-FLAG 

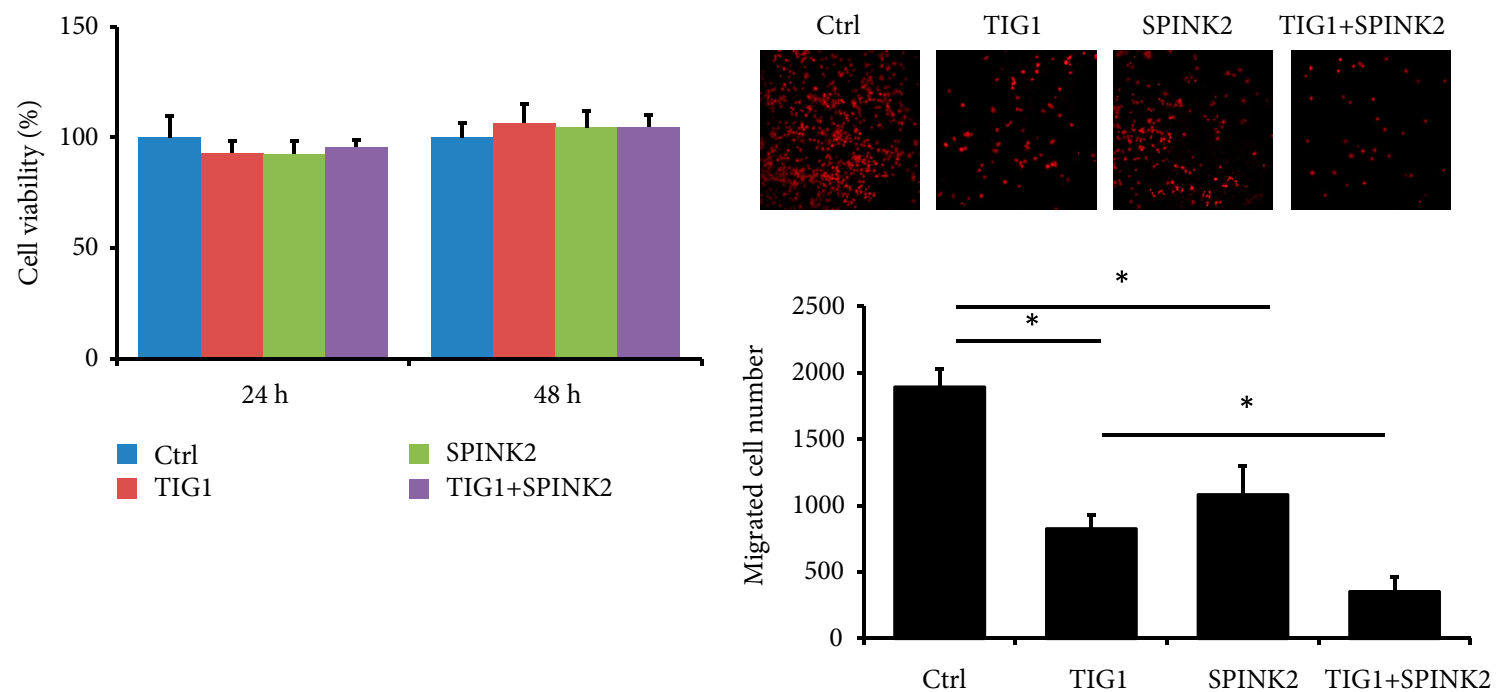

(a)
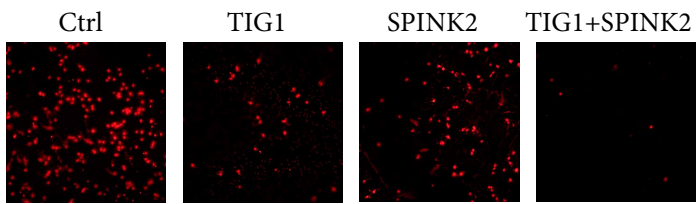

(b)

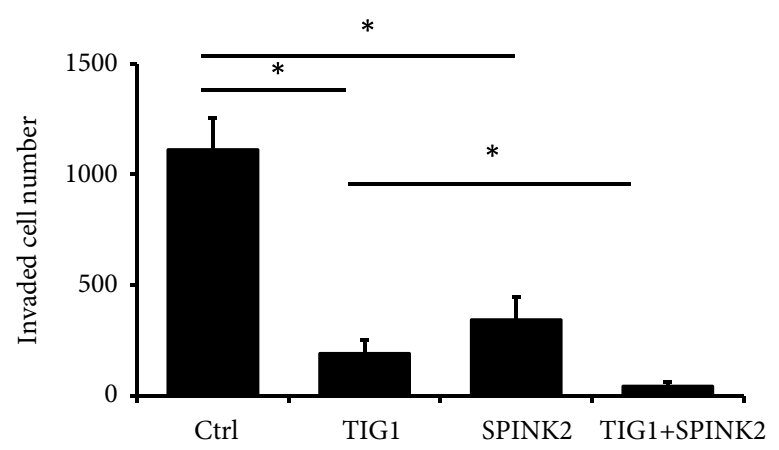

(c)

FIGURE 2: TIG1 and SPINK2 suppress cell migration and invasion. NT2/D1 cells were plated in triplicate in 24-well plates. After cells were transfected with TIG1-myc-his and SPINK2-flag expression vectors for $24 \mathrm{~h}$, cells were serum starved for $12 \mathrm{~h}$ and were then incubated in medium containing $1 \%$ FBS for $24 \mathrm{~h}$. Cell viability was determined by a WST-1 assay (a). NT2/D1 cells were transfected with the indicated expression vectors for $24 \mathrm{~h}$. After serum starvation for $12 \mathrm{~h}$, cells were added in triplicate into the upper transwell insert. Culture medium containing $20 \%$ FBS was used as a chemoattractant in the lower wells. Migratory cells (b), and invading cells (c) were stained with PI after $24 \mathrm{~h}$ incubation. Representative results from three independent experiments are shown, and the data are presented as the mean \pm SD. ${ }^{*} p<0.05$.

antibody (Figure 3(a)). In addition to overexpression of TIG1 and SPINK2, we also examined the interaction between endogenous TIG1 and SPINK2 using TIG1- or SPINK2-specific antibodies. Coimmunoprecipitation results confirmed that endogenous TIG1 associates with SPINK2 (Figure 3(b)). We further verified sublocalization of TIG1 and SPINK2 within cells. Immunofluorescence staining images revealed that both TIG1 and SPINK2 exhibited punctate distribution at perinuclear organelles, and most TIG1 and SPINK2 proteins were colocalized (yellow) in cotransfected NT2/D1 cells (Figure 4).

3.4. TIG1 Suppresses EMT. The SPINK2 homolog has been shown to inhibit cell metastasis by suppressing levels of uPA protein in ovarian cells [22]; we next determined whether expression of TIG1 or SPINK2 in NT2/D1 cells affects the activity of uPA. Expressing TIG1 and SPINK2 in NT2/D1 cells led to downregulation of uPA activity by $33 \%$ and $18.9 \%$, respectively. Coexpressing SPINK2 further promoted TIG1mediated suppression of uPA activity by $63.7 \%$ (Figure 5(a) and Supplementary Table S2). Having found that the uPA system is involved in EMT processes, we next examined the effects of TIG1 and SPINK2 on expression of E-cadherin and vimentin. Expression of TIG1 and SPINK2 resulted in increased E-cadherin protein levels by 1.35 - and 1.34-fold, respectively, while levels of vimentin were decreased by $12.3 \%$ in TIG1-expressing cells (Figure 5(b)). Levels of E-cadherin 

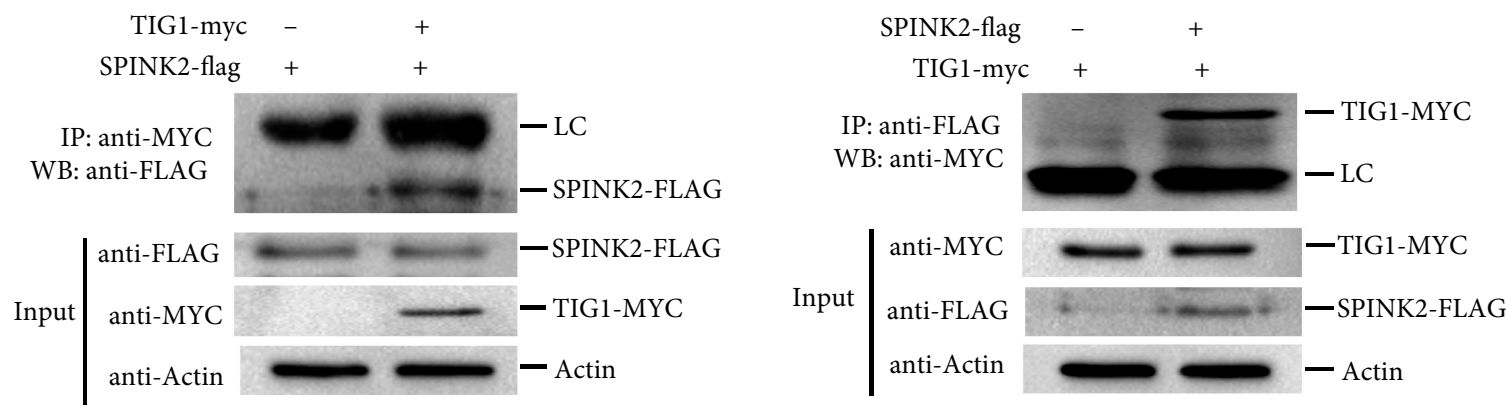

(a)
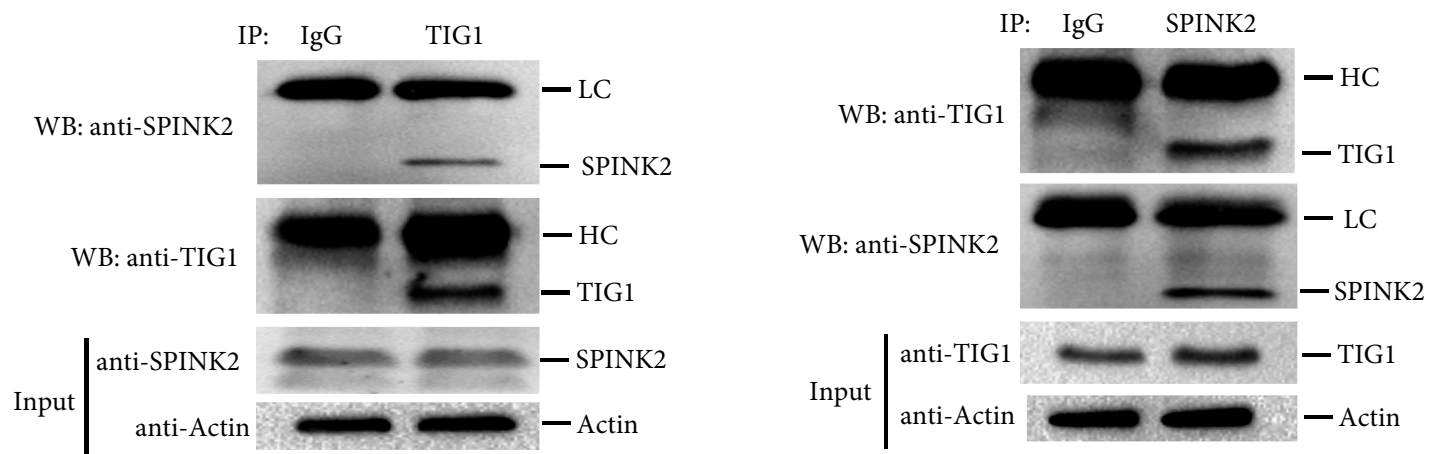

(b)

FIgURE 3: TIG1 associates with SPINK2. Cell lysates were prepared from NT2/D1 cells transfected with TIG1-myc-his and SPINK2-flag expression vectors for $24 \mathrm{~h}$. The interaction between TIG1-MYC and SPINK2-FLAG was analyzed by coimmunoprecipitation and western blot analysis using anti-MYC or anti-FLAG antibodies (a). Cell lysates were prepared from NT2/D1 cells, and the interaction between TIG1 and SPINK2 was analyzed by coimmunoprecipitation using anti-TIG1 or anti-SPINK2 antibodies followed by western blot analysis (b).

were enhanced by $20.9 \%$ in NT2/D1 cells coexpressing TIG1 and SPINK2 compared to levels in TIG1-expressing cells (Figure 5(b)).

\subsection{SPINK2 Silencing Alleviates TIG1-Mediated EMT} Suppression. Since SPINK2 enhanced TIG1-mediated E-cadherin expression, we next examined whether knockdown of SPINK2 would affect TIG1-mediated EMT processes. uPA activity was decreased by $34.9 \%$ in TIG1-expressing NT2/D1 cells, and silencing of SPINK2 significantly alleviated TIG1mediated uPA activity suppression by $73.7 \%$ (Figure 6(a)). Furthermore, enhanced levels of E-cadherin by TIG1 were decreased by $63.5 \%$ in TIG1-expressing cells cotransfected with SPINK2 siRNA (Figure 6(b)). Decreased levels of vimentin in response to TIG1 expression were also restored by $55.1 \%$ in TIG1- and SPINK2-siRNA coexpressing cells (Figure 6(b) and Supplementary Table S3). In addition, silencing expression of SPINK2 significantly alleviated TIG1-mediated cell migration and invasion suppression by $51.1 \%$ (Figure 7(a) and Supplementary Table S4) and 64.2\% (Figure 7(b) and Supplementary Table S4), respectively.

\section{Discussion}

Our results indicate that expression of TIG1 in NT2/D1 testicular carcinoma cells leads to decreased uPA activity, EMT reduction, and inhibition of cell migration and invasion. We also found that TIG1 interacts with SPINK2 within cells, and coexpression of SPINK2 enhanced TIG1-mediated inhibition of uPA activity and cell invasion, while TIG1-mediated cell invasion was reversed in SPINK2-silenced cells. These observations suggest that TIG1 regulates testis cell invasion and migration and may influence the uPA system via interaction with the SPINK2 protein.

A previous study showed that TIG1 induces expression of GRK5, subsequently decreasing cell proliferation and increasing cell death in colorectal carcinoma cells [9]. However, TIG1-induced decreases in cell viability were not observed in TIG1-expressing NT2/D1 testicular carcinoma cells. Furthermore, no apparent changes in cell morphology were observed when TIG1 was expressed in NT2/D1 cells (Figure 4). The different fates that occur in distinct subtypes of cancer cells expressing TIG1 might be caused by TIG1-targeting proteins. Moreover, regulation of the uPA system by TIG1 in testis cells may not occur in other cancer cells because SPINK2 is expressed in testis tissue only (Figure 1).

In mammalian cells, serine proteases can be broadly classified into secreted proteases and membrane-anchored proteases. Secreted serine proteases, such as uPA, have been shown to regulate a range of biological events, including tissue repair, the immune system, and nutrient uptake. In contrast, membrane-anchored proteases, such as GPIanchored UPAR, have roles in various physiological events, including the epithelial barrier, embryonic development, and tissue differentiation [24]. Dysregulated expression of the uPA/uPAR system results in cell invasion in multiple 

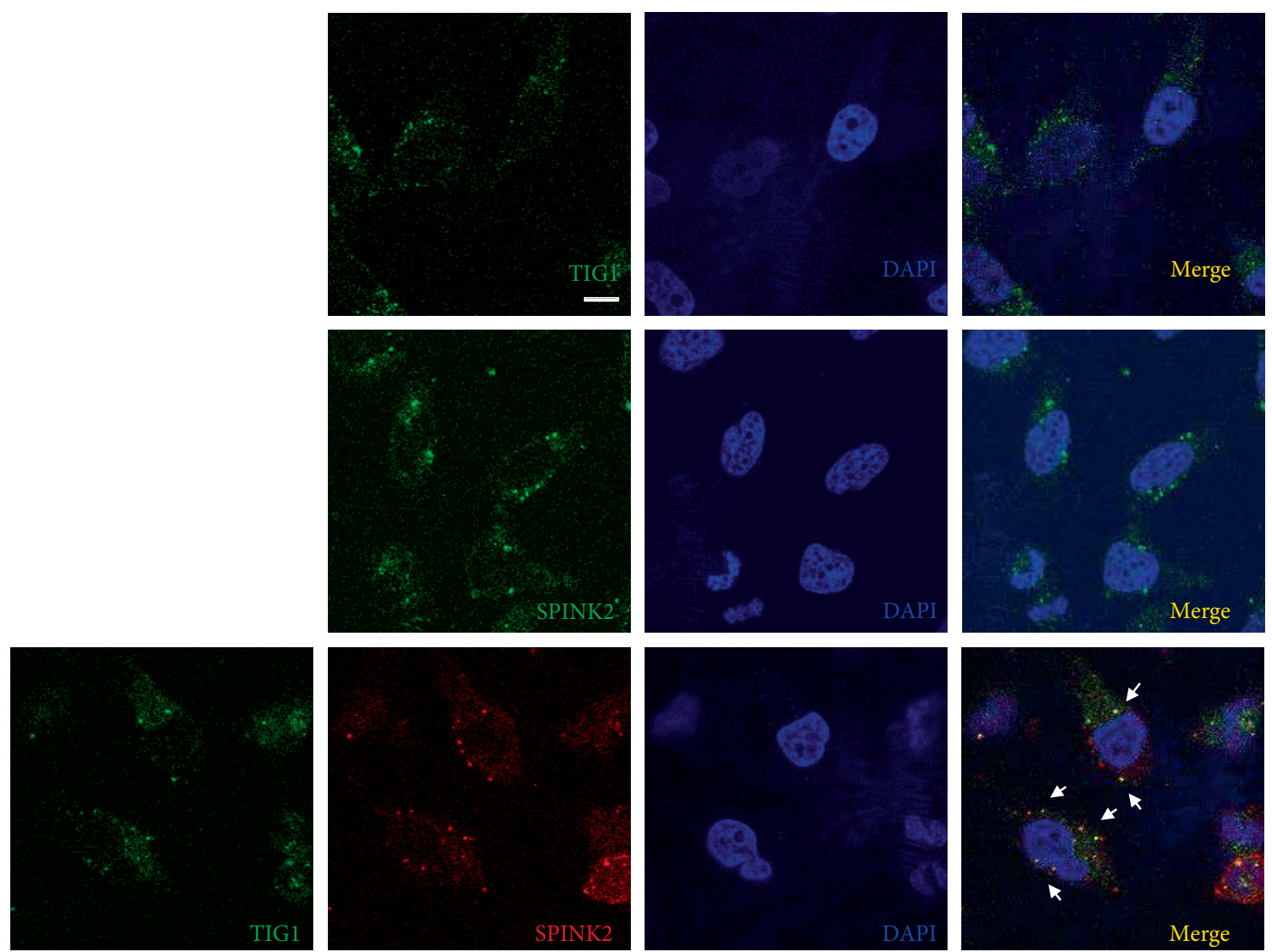

FIGURE 4: TIG1 co-localizes with SPINK2. NT2/D1 cells were cotransfected with TIG1-myc-his and SPINK2-flag expression vectors for 24h. After fixation with $4 \%$ paraformaldehyde and permeabilization, cells were incubated with anti-MYC and anti-FLAG antibodies followed by incubation with an Alexa Fluor 488-conjugated goat anti-rabbit IgG or an Alexa Fluor 633-conjugated goat anti-mouse IgG antibody. After washing with 1x PBS, cells were stained with DAPI and were then analyzed for TIG1-MYC and SPINK2-FLAG expression with a confocal microscope. Scale bar: $10 \mu \mathrm{m}$.

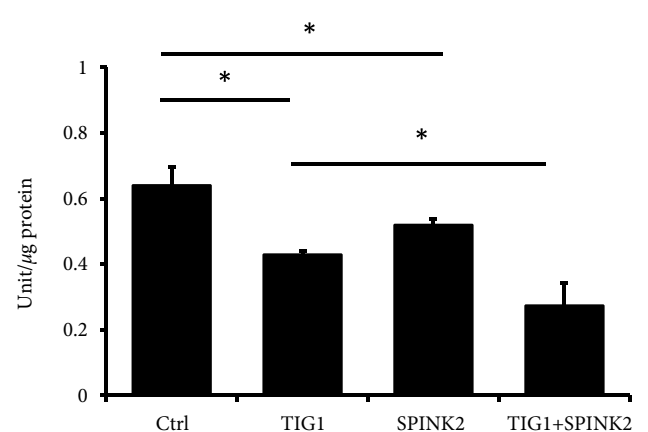

(a)

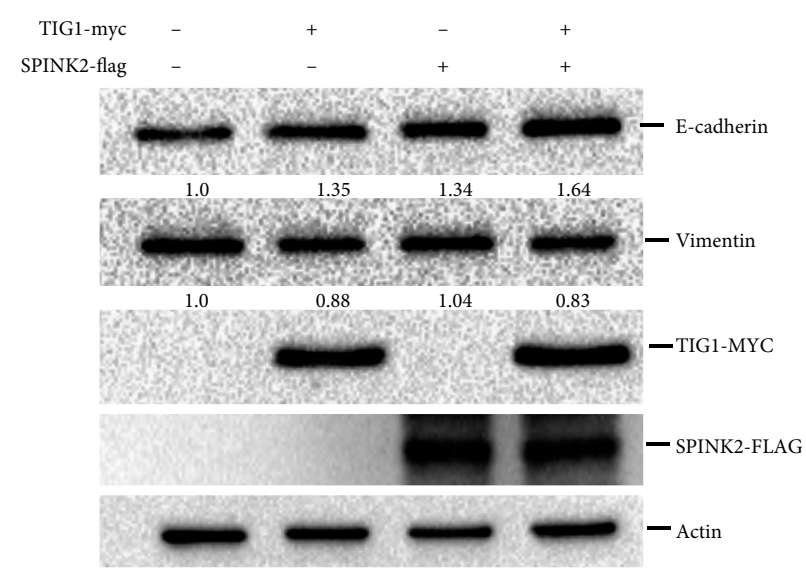

(b)

FIGURE 5: TIG1 and SPINK2 inhibit EMT. NT2/D1 cells were transfected with TIG1-myc-his and SPINK2-flag expression vectors for 24 h and were serum starved for $24 \mathrm{~h}$. Cell lysates were prepared, and uPA activity was measured by enzyme immunoassay. Representative results from three independent experiments are shown, and data are presented as the mean $\pm \mathrm{SD} .{ }^{*} p<0.05$ (a). Cell lysates from NT2/D1 cells transfected with TIG1-myc-his and SPINK2-flag expression vectors were prepared. Expression levels of E-cadherin, vimentin, TIG1-MYC, and SPINK2-FLAG were determined by western blot analysis.

cancer cell lines [25-31]. In contrast, expression levels of UPA and UPAR have been shown to be increased in testicular germ cell tumors compared to levels in adjacent normal tissues [32]. This suggests that the uPA/uPAR system has an important role in cancer growth and tumorigenesis in testis tissue. 


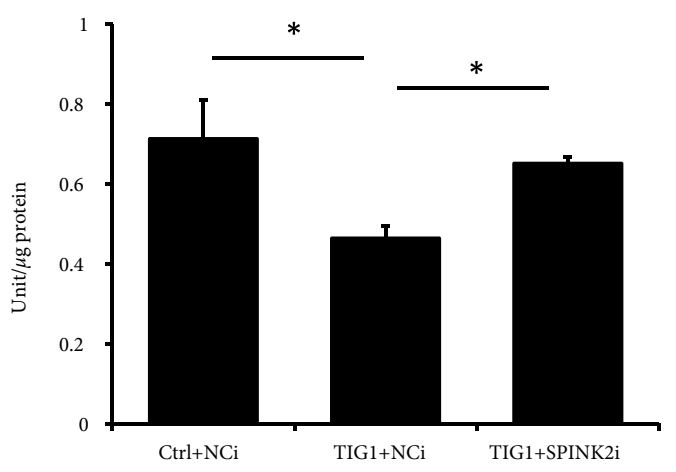

(a)

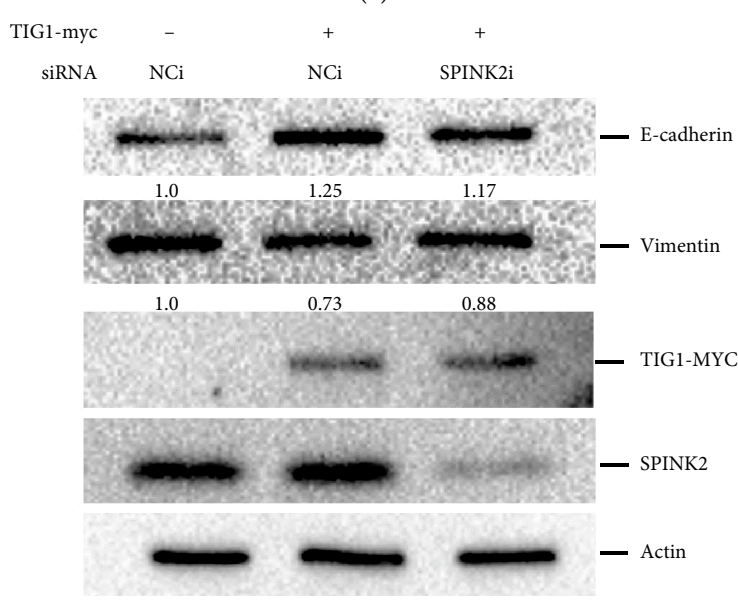

(b)

FIGURE 6: SPINK2 siRNAs alleviate TIG1-regulated EMT. NT2/D1 cells were transfected with TIG1-myc-his expression vector along with control $(\mathrm{NCi})$ or SPINK2 siRNAs for $24 \mathrm{~h}$ and were serum starved for $24 \mathrm{~h}$. Cell lysates were prepared, and uPA activity was measured by enzyme immunoassay. Representative results from three independent experiments are shown, and data are presented as the mean \pm SD. ${ }^{*} p<0.05$ (a). Cell lysates from NT2/D1 cells transfected with TIG1-myc-his expression vector along with NCi or SPINK2 siRNAs were prepared. Expression levels of E-cadherin, vimentin, TIG1-MYC, and SPINK2 were determined by western blot analysis.

SPINK1 was first as a member of the Kazal domain-containing protein family [33]. The primary function of SPINK1 is to serve as a pancreatic and intestinal serine protease inhibitor and to balance levels of trypsinogen and trypsin. However, SPINK1 overexpression, which was observed in different types of cancer [34], may be partially due to SPINK1 having structural homology with the epidermal growth factor $[18,35,36]$. In contrast to SPINK1, there are few reports in the literature concerning the role of SPINK2 on normal physiological function or tumorigenesis. The tissue-specific distribution of SPINK2 may be the cause. Although the role of SPINK2 in the testis is still not clear, SPINK2 might regulate cell migration and invasion in testicular cancer cells through the uPA/uPAR system; this is supported firstly by the similar activity of homologous proteins [21, 22]. Second, our current study observed an interaction between TIG1 and SPINK2, and the association of these two proteins was involved in suppressing
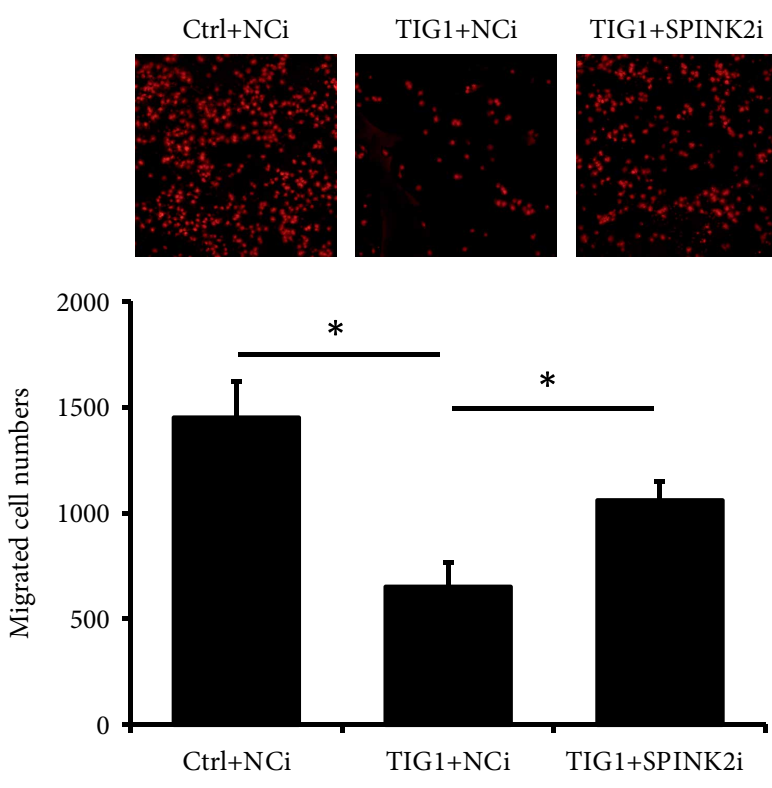

(a)
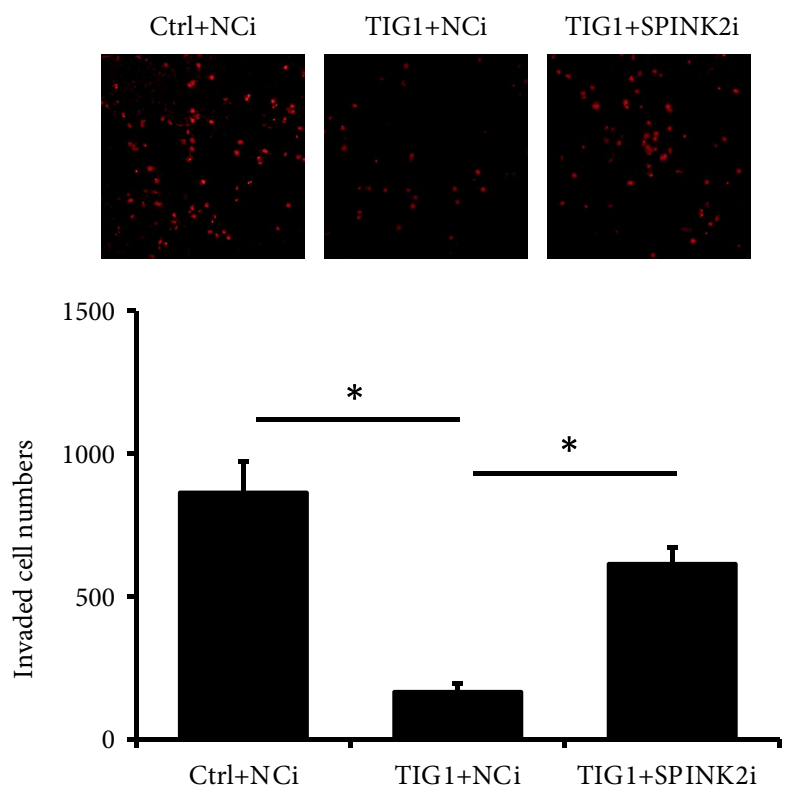

(b)

FIgURE 7: SPINK2 siRNAs alleviate TIG-regulated cell migration and invasion. NT2/D1 cells were transfected with TIG1-myc-his expression vectors along with NCi or SPINK2 siRNAs for $24 \mathrm{~h}$ and were serum starved for $12 \mathrm{~h}$. Migratory cells (a) and invading cells (b) were stained with PI after $24 \mathrm{~h}$ incubation. Representative results from three independent experiments are shown, and data are presented as mean \pm SD. ${ }^{*} p<0.05$.

the activity of uPA and subsequent effects on EMT and cell migration in testis cancer cells.

Our study demonstrated that expression of TIG1 inhibits cell migration and invasion in testicular carcinoma cells. SPINK2 can interact with TIG1 and enhance TIG1-mediated EMT suppression. Silencing of SPINK2 alleviated the effects induced by TIG1 in testicular carcinoma cells. These results suggest that TIG1 and SPINK2 can be developed as novel 
molecular targets to prevent metastasis of testicular carcinoma.

\section{Data Availability}

All data used to support the findings of this study are included within the article.

\section{Conflicts of Interest}

The authors declare that they have no conflicts of interest.

\section{Acknowledgments}

This study was supported by a grant (TCRD-TPE-108-59) from the Taipei Tzuchi Hospital through the Buddhist TzuchiMedical Foundation, Taipei, Taiwan. The authors thank the Core Laboratory of the Buddhist Tzuchi General Hospital for support.

\section{Supplementary Materials}

Supplementary Table 1. TIG1 and SPINK2 suppress NT2/ D1 cell migration and invasion. Supplementary Table 2. Effect of TIG1 and SPINK2 on uPA activity in NT2/D1 cells. Supplementary Table 3. Effect of SPINK2 siRNA on TIG1regulated uPA activity in NT2/D1 cells. Supplementary Table 4. SPINK2 siRNA alleviates TIG-regulated cell migration and invasion. (Supplementary Materials)

\section{References}

[1] S. Nagpal, S. Patel, A. T. Asano, A. T. Johnson, M. Duvic, and R. A. Chandraratna, "Tazarotene-induced gene 1 (TIG1), a novel retinoic acid receptor-responsive gene in skin," Journal of Investigative Dermatology, vol. 106, no. 2, pp. 269-274, 1996.

[2] J. Zhang, L. Liu, and G. P. Pfeifer, "Methylation of the retinoid response gene TIG1 in prostate cancer correlates with methylation of the retinoic acid receptor beta gene," Oncogene, vol. 23, no. 12, pp. 2241-2249, 2004.

[3] M. Shutoh, N. Oue, P. P. Aung et al., "DNA methylation of genes linked with retinoid signaling in gastric carcinoma: expression of the retinoid acid receptor beta, cellular retinol-binding protein 1 , and tazarotene-induced gene 1 genes is associated with DNA methylation," Cancer, vol. 104, no. 8, pp. 1609-1619, 2005.

[4] H. Mizuiri, K. Yoshida, T. Toge et al., "DNA methylation of genes linked to retinoid signaling in squamous cell carcinoma of the esophagus: DNA methylation of CRBP1 and TIG1 is associated with tumor stage," Cancer Science, vol. 96, no. 9, pp. 571-577, 2005.

[5] N. Takai, N. Kawamata, C. S. Walsh et al., "Discovery of epigenetically masked tumor suppressor genes in endometrial cancer," Molecular Cancer Research, vol. 3, no. 5, pp. 261-269, 2005.

[6] M. Nowacka-Zawisza and E. Wisnik, "DNA methylation and histone modifications as epigenetic regulation in prostate cancer (Review)," Oncology Reports, vol. 38, no. 5, pp. 2587-2596, 2017.
[7] X.-H. Chen, W.-G. Wu, and J. Ding, "Aberrant TIG1 methylation associated with its decreased expression and clinicopathological significance in hepatocellular carcinoma," Tumor Biology, vol. 35, no. 2, pp. 967-971, 2014.

[8] Z. J. Sahab, M. D. Hall, Y. Me Sung et al., “Tumor suppressor RARRES1 interacts with cytoplasmic carboxypeptidase AGBL2 to regulate the alpha-tubulin tyrosination cycle," Cancer Research, vol. 71, no. 4, pp. 1219-1228, 2011.

[9] C.-C. Wu, F.-M. Tsai, R.-Y. Shyu, Y.-M. Tsai, C.-H. Wang, and S.-Y. Jiang, "G protein-coupled receptor kinase 5 mediates Tazarotene-induced gene 1-induced growth suppression of human colon cancer cells," BMC Cancer, vol. 11, p. 175, 2011.

[10] F.-M. Tsai, C.-C. Wu, R.-Y. Shyu, C.-H. Wang, and S.-Y. Jiang, "Tazarotene-induced gene 1 inhibits prostaglandin E2-stimulated HCT116 colon cancer cell growth," Journal of Biomedical Science, vol. 18, no. 1, p. 88, 2011.

[11] C. H. Wang, R. Y. Shyu, C. C. Wu et al., "Tazarotene-Induced Gene 1 Interacts with DNAJC8 and Regulates Glycolysis in Cervical Cancer Cells," Molecules and Cells, vol. 41, no. 6, pp. 562-574, 2018.

[12] R.-Y. Shyu, C.-H. Wang, C.-C. Wu et al., "TazaroteneInduced Gene 1 Enhanced Cervical Cell Autophagy through Transmembrane Protein 192," Molecules and Cells, vol. 39, no. 12, pp. 877-887, 2016.

[13] W. K. Kwok, J. C. Pang, K. W. Lo, and H.-K. Ng, "Role of the RARRES1 gene in nasopharyngeal carcinoma," Cancer Genetics and Cytogenetics, vol. 194, no. 1, pp. 58-64, 2009.

[14] W. Taccone, W. Mazzon, and M. Belli, "Evaluation of TATI and other markers in solid tumors," Scandinavian Journal of Clinical and Laboratory Investigation, Supplement, vol. 51, no. 207, pp. 25-32, 1991.

[15] S. A. Tomlins, D. R. Rhodes, J. Yu et al., "The role of SPINK1 in ETS rearrangement-negative prostate cancers," Cancer Cell, vol. 13, no. 6, pp. 519-528, 2008.

[16] Y. Ohmachi, A. Murata, N. Matsuura et al., "Specific expression of the pancreatic-secretory-trypsin-inhibitor (PSTI) gene in hepatocellular carcinoma," International Journal of Cancer, vol. 55, no. 5, pp. 728-734, 1993.

[17] H. A. El-mezayen, F. M. Metwally, and H. Darwish, "A novel discriminant score based on tumor-associated trypsin inhibitor for accurate diagnosis of metastasis in patients with breast cancer," Tumor Biology, vol. 35, no. 3, pp. 2759-2767, 2014.

[18] Y. T. Chen, S. C. Tsao, S. S. Yuan, H. P. Tsai, and C. Y. Chai, "Serine protease inhibitor kazal type 1 (SPINK1) promotes proliferation of colorectal cancer through the epidermal growth factor as a prognostic marker," Pathology \& Oncology Research, vol. 21, no. 4, pp. 1201-1208, 2015.

[19] K. Ge, J. Huang, W. Wang et al., "Serine protease inhibitor kazal-type 6 inhibits tumorigenesis of human hepatocellular carcinoma cells via its extracellular action," Oncotarget, vol. 8, no. 4, pp. 5965-5975, 2017.

[20] N. Emami and E. P. Diamandis, "New insights into the functional mechanisms and clinical applications of the kallikrein-related peptidase family," Molecular Oncology, vol. 1, no. 3, pp. 269-287, 2007.

[21] N. P. Azouz, M. A. Ynga-Durand, J. M. Caldwell et al., "The antiprotease SPINK7 serves as an inhibitory checkpoint for esophageal epithelial inflammatory responses," Science Translational Medicine, vol. 10, no. 444, Article ID eaap9736, 2018.

[22] S. Cai, P. Zhang, S. Dong, L. Li, J. Cai, and M. Xu, “Downregulation of SPINK13 promotes metastasis by regulating uPA in ovarian 
cancer cells," Cellular Physiology and Biochemistry, vol. 45, no. 3, pp. 1061-1071, 2018.

[23] A. Aagaard, P. Listwan, N. Cowieson et al., "An inflammatory role for the mammalian carboxypeptidase inhibitor latexin: relationship to cystatins and the tumor suppressor TIG1," Structure, vol. 13, no. 2, pp. 309-317, 2005.

[24] X. S. Puente, L. M. Sánchez, A. Gutiérrez-Fernández, G. Velasco, and C. López-Otín, "A genomic view of the complexity of mammalian proteolytic systems," Biochemical Society Transactions, vol. 33, no. 2, pp. 331-334, 2005.

[25] G. E. Stillfried, D. N. Saunders, and M. Ranson, "Plasminogen binding and activation at the breast cancer cell surface: the integral role of urokinase activity," Breast Cancer Research, vol. 9, no. 1, 2007.

[26] T. Oka, T. Ishida, T. Nishino, and K. Sugimachi, "Immunohistochemical evidence of urokinase-type plasminogen activator in primary and metastatic tumors of pulmonary adenocarcinoma," Cancer Research, vol. 51, no. 13, pp. 3522-3525, 1991.

[27] Y. Hasui, K. Marutsuka, J. Suzumiya, S. Kitada, Y. Osada, and A. Sumiyoshi, "The content of urokinase-type plasminogen activator antigen as a prognostic factor in urinary bladder cancer," International Journal of Cancer, vol. 50, no. 6, pp. 871-873, 1992.

[28] H. Nekarda, J. R. Siewert, M. Schmitt, and K. Ulm, “Tumourassociated proteolytic factors uPA and PAI-1 and survival in totally resected gastric cancer," Lancet, vol. 343 , no. 8889 , p. 117, 1994.

[29] M. J. Duffy, P. M. McGowan, N. Harbeck, C. Thomssen, and M. Schmitt, "uPA and PAI-1 as biomarkers in breast cancer: validated for clinical use in level-of-evidence-1 studies," Breast Cancer Research, vol. 16, no. 4, p. 428, 2014.

[30] W. Harms, W. Malter, S. Kramer, U. Drebber, A. Drzezga, and M. Schmidt, "Clinical significance of urokinase-type plasminogen activator (uPA) and its type-1 inhibitor (PAI-1) for metastatic sentinel lymph node involvement in breast cancer," Anticancer Research, vol. 34, no. 8, pp. 4457-4462, 2014.

[31] M. Banys-Paluchowski, I. Witzel, B. Aktas et al., "The prognostic relevance of urokinase-type plasminogen activator (uPA) in the blood of patients with metastatic breast cancer," Scientific Reports, vol. 9, no. 1, 2019.

[32] S. Ulisse, E. Baldini, M. Mottolese et al., "Increased expression of urokinase plasminogen activator and its cognate receptor in human seminomas," BMC Cancer, vol. 10, no. 1, 2010.

[33] L. A. Kazal, D. S. Spicer, and R. A. Brahinsky, "Isolation of a crystalline trypsin inhibitor-anticoagulant protein from pancreas," Journal of The American Chemical Society, vol. 70, no. 9, pp. 3034-3040, 1948.

[34] K. Rasanen, O. Itkonen, H. Koistinen, and U. H. Stenman, "Emerging Roles of SPINK1 in Cancer," Clinical Chemistry, vol. 62, no. 3, pp. 449-457, 2016.

[35] N. Ozaki, M. Ohmuraya, M. Hirota et al., "Serine protease inhibitor Kazal type 1 promotes proliferation of pancreatic cancer cells through the epidermal growth factor receptor," Molecular Cancer Research, vol. 7, no. 9, pp. 1572-1581, 2009.

[36] W. L. McKeehan, Y. Sakagami, H. Hoshi, and K. A. McKeehan, "Two apparent human endothelial cell growth factors from human hepatoma cells are tumor-associated proteinase inhibitors," Journal of Biological Chemistry, vol. 261, no. 12, pp. 5378-5383, 1986. 


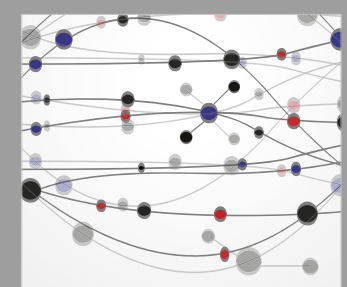

The Scientific World Journal
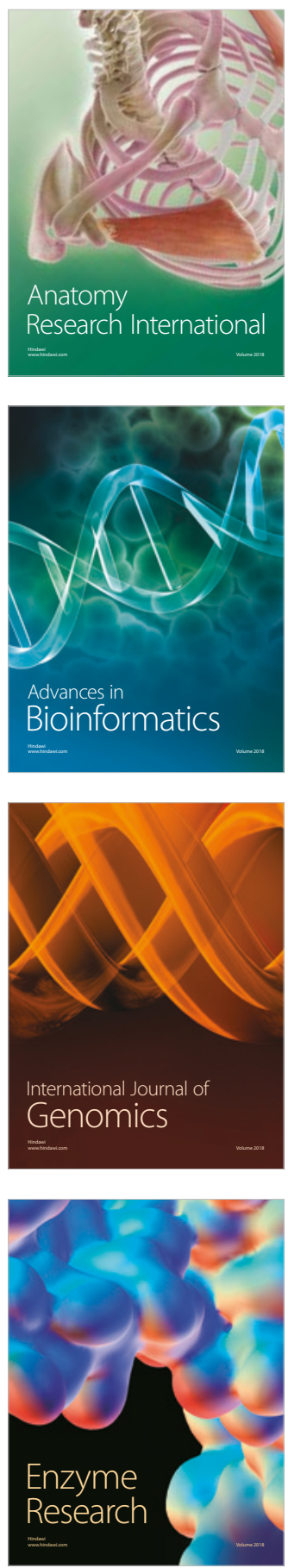
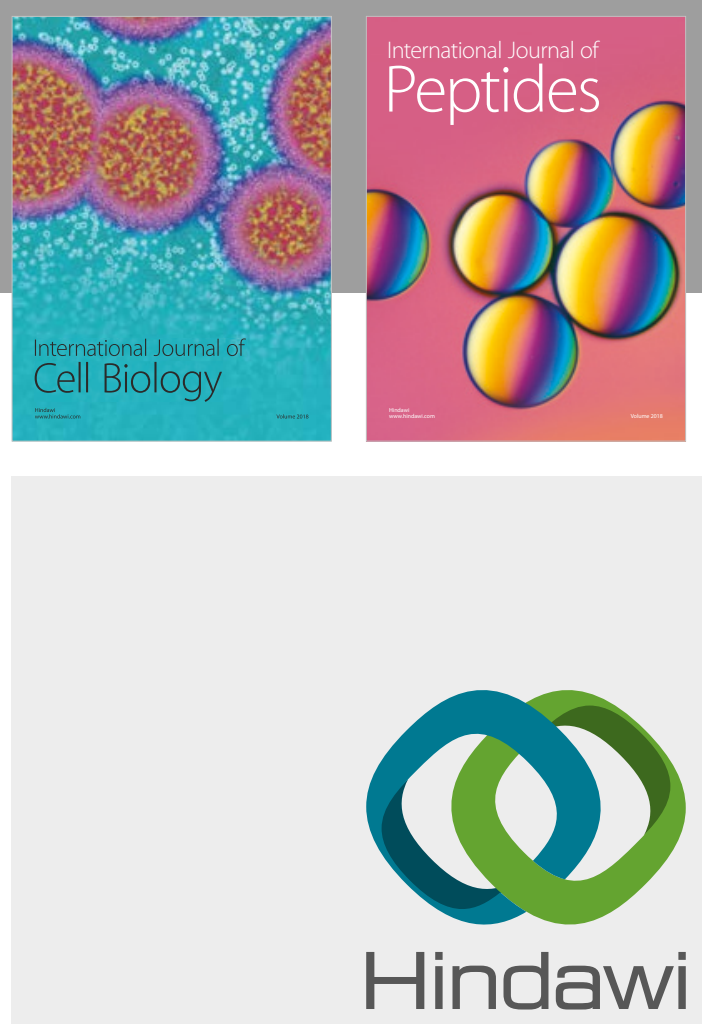

Submit your manuscripts at

www.hindawi.com
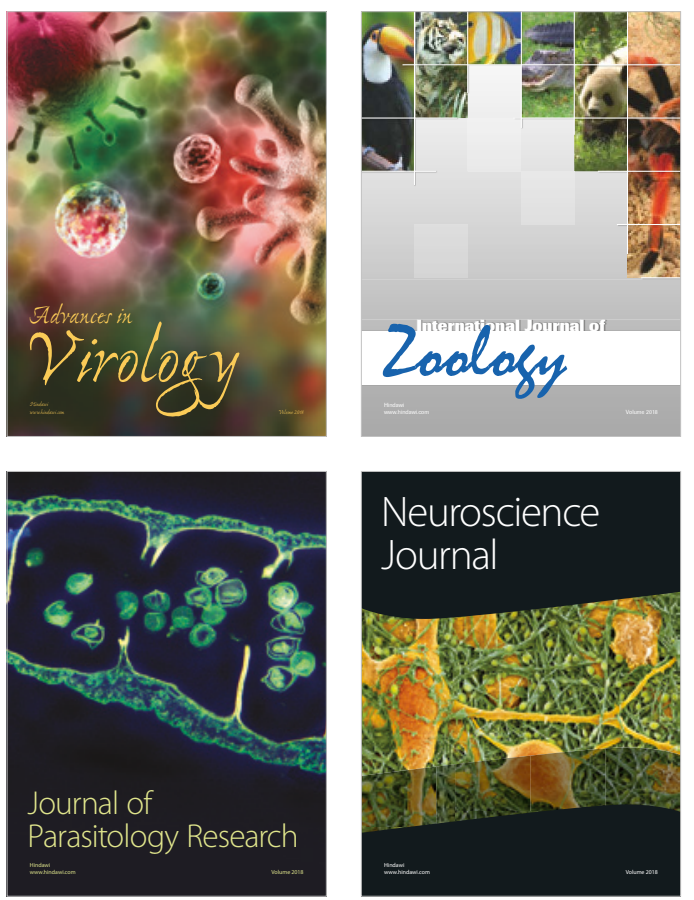
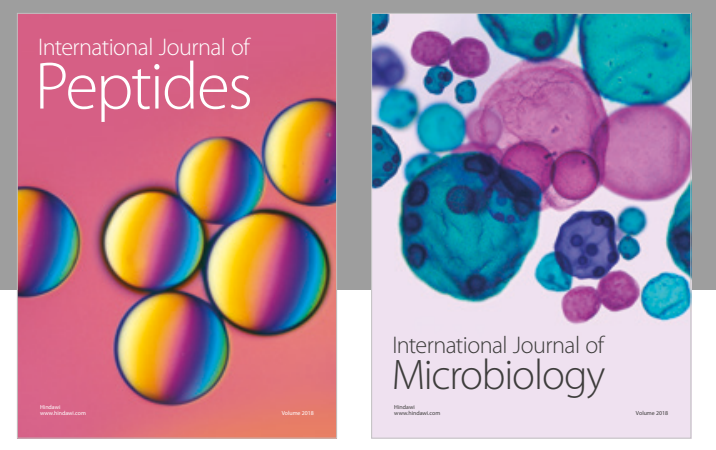

nternational Journal of Microbiology
Journal of
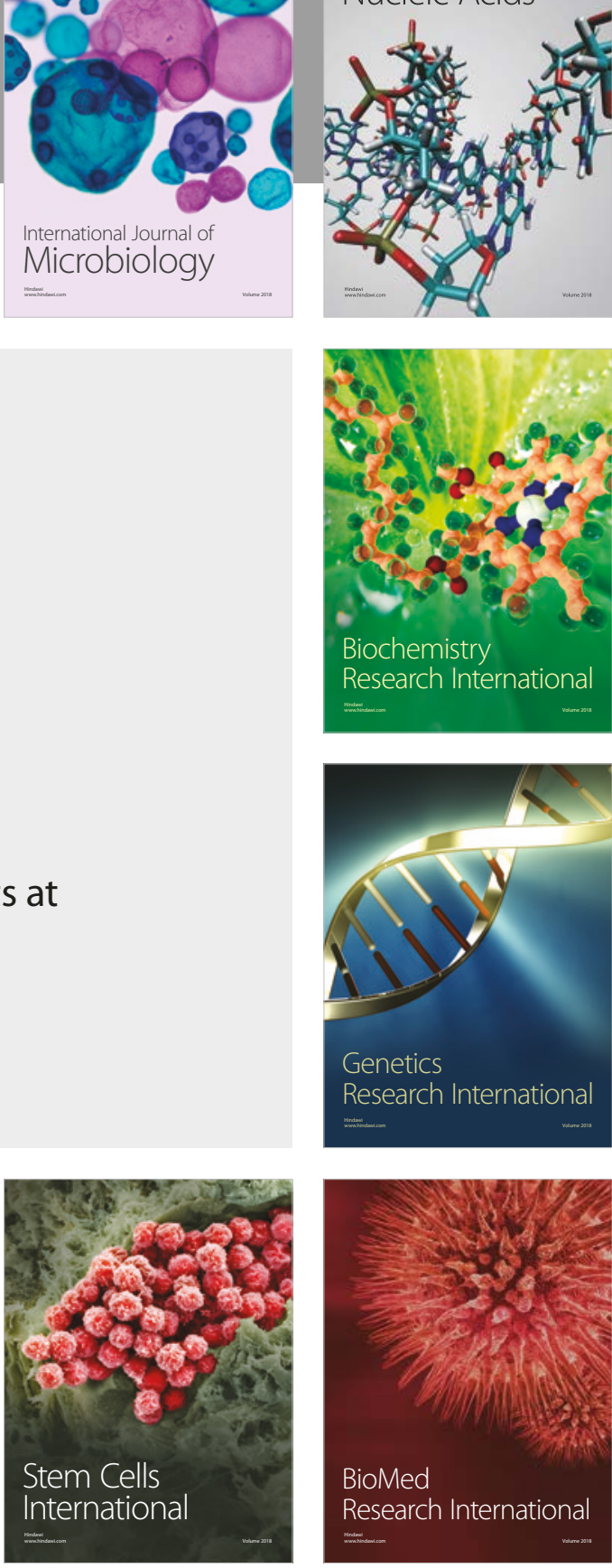
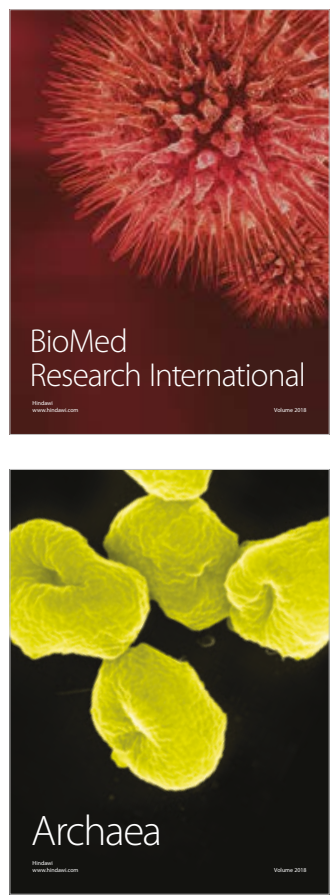